\title{
Identifying N-linked glycan moiety and motifs in the cysteine-rich domain critical for N-glycosylation and intracellular trafficking of SR-AI and MARCO
}

Huey-Jen Tsay ${ }^{1 \dagger}$, Yung-Cheng Huang ${ }^{2 \dagger}$, Yi-Jen Chen', Yun-Hao Lee', Shu-Meng Hsu', Keng-Chang Tsai ${ }^{3}$, Cheng-Ning Yang ${ }^{4}$, Fong-Lee Huang ${ }^{4}$, Feng-Shiun Shie ${ }^{5}$, Lin-Chien Lee ${ }^{6 *}$ and Young-Ji Shiao ${ }^{7,8^{*}}$

\begin{abstract}
Background: The accumulation of soluble oligomeric amyloid- $\beta$ peptide (OA $\beta$ ) proceeding the formation of senile plaques contributes to synaptic and memory deficits in Alzheimer's disease. Our previous studies have indentified scavenger receptor A (SR-A), especially SR-A type I (SR-Al), as prominent scavenger receptors on mediating oA $\beta$ clearance by microglia while glycan moiety and scavenger receptor cysteine-rich (SRCR) domain may play the critical role. Macrophage receptor with collagenous structure (MARCO), another member of class A superfamily with a highly conserved SRCR domain, may also play the similar role on oA $\beta$ internalization. However, the role of N-glycosylation and SRCR domain of SR-Al and MARCO on OA $\beta$ internalization remains unclear.

Result: We found that oA $\beta$ internalization was diminished in the cells expressing SR-Al harboring mutations of dual N-glycosylation sites (i.e. N120Q-N143Q and N143Q-N184Q) while they were normally surface targeted. Normal OA $\beta$ internalization was observed in 10 SR-AI-SRCR and 4 MARCO-SRCR surface targeted mutants. Alternatively, the SRCR mutants at $\beta$-sheet and a-helix and on disulfide bone formation obstructed receptor's $\mathrm{N}$-glycosylation and surface targeting.
\end{abstract}

Conclusion: Our study reveals that N-glycan moiety is more critical than SRCR domain for SR-A-mediated oA $\beta$ internalization.

Keywords: Scavenger receptor A, MARCO, SRCR domain, N-glycosylation, Alzheimer's disease, oligomeric $\beta$-amyloid

\section{Background}

Activated scavenger receptor A (SR-A) promotes glial internalization of Amyloid- $\beta$ peptide $(A \beta)$, which is a key histopathological characteristic of Alzheimer's disease (AD) $[1,2]$. Previously, we identified SR-A as the prominent subtype of scavenger receptor mediating oligomeric $A \beta(o A \beta)$ internalization in microglia, and revealed that the cysteinerich (SRCR) domain of SR-A type I (SR-AI) may be the

\footnotetext{
* Correspondence: swordtop@yahoo.com.tw; yshiao@nricm.edu.tw ${ }^{\dagger}$ Equal contributors

${ }^{6}$ Department of Physical Medicine and Rehabilitation, Cheng Hsin General Hospital, Taipei 11220, Taiwan, R.O.C

${ }^{7}$ Division of Basic Chinese Medicine, National Research Institute of Chinese Medicine, Taipei 11221, Taiwan, R.O.C

Full list of author information is available at the end of the article
}

critical domain on modulating the efficacy of surface targeting and mediating $\mathrm{OA} \beta$ internalization $[3,4]$.

SR-AI contains six domains: a cytoplasmic domain, a transmembrane domain, a spacer region, an $\alpha$-helical coiled-coil domain, a collagenous domain, and a Cterminal SRCR domain [5]. The cytoplasmic domain of SR-A has been identified to involve in cell adhesion and receptor internalization [6]. The critical amino acids in cytoplasmic domain involving SR-A surface targeting and interaction with signaling molecules have been identified $[7,8]$. Seven residues in the $\alpha$-helical coiled-coil domain mediate the formation of the trimeric coiled-coil structure [9]. The collagenous domain mediates binding to the extracellular matrix [10], and point mutations in the positively charged lysine clusters 
in the SR-A type II collagenous domain have been shown to decrease acetylated-LDL (AcLDL) binding activity [11]. Macrophage receptor with collagenous structure (MARCO), another SRCR-containing group A receptor, shows the same overall domain structure as the SR-AI but differs in having a longer extracellular domain and completely lacking an $\alpha$-helical coiled-coil domain [12]. The schematic representation of human SR-AI and MARCO were shown in Fig. 1a. The modeled structures and surface electrostatic potential of the SRCR domain of human SR-AI and MARCO were shown in Fig. 1b. The sequence of the SRCR domain is highly conserved between human SR-AI and human MARCO ([13], Fig. 1c). Examination of the crystal structure of the mouse MARCO SRCR domain revealed that the monomeric recombinant SRCR domain possess a compact and globular conformation, which was identified as the binding domain for bacteria, AcLDL, and the extracellular matrix $[14,15]$.

Protein glycosylation have important biological functions in protein folding and stability, cell adhesion, receptor targeting and ligand binding [16]. Previous study of SR-A showed that murine SR-A-mediated AcLDL uptake was not significantly affected even though the $\mathrm{N}$-linked glycosylation of SR-A is prevented [17]. The surface-targeted SR-A remains at high mannose status, suggested that the absence of complex $\mathrm{N}$-glycan does not impair the trafficking and AcLDL uptake of SR-A. However, the molecular mechanisms underlying SR-AI activity and the relationship of the structure of SR-AI to its functions are not well-understood. Previous studies have conducted several studies involving the generation and characterization of SR-BI mutants [18]. Some of these studies have shown that the large, extracellular loop of SR-BI, which is glycosylated, plays a critical role in mediating not only ligand binding but also the selective lipid uptake step [18]. The functional role of the extensive $N$-linked glycosylation of SR-BI has also been explored [19].

Previous studies have demonstrated that microglia take up and degrade soluble and fibrillar $A \beta$ in different ways. Soluble $A \beta$ is internalized into microglia through constitutive, non-saturable, and fluid phase macropinocytosis, and the internalized soluble $A \beta$ is rapidly delivered to the lysosomes by the late endolytic pathway [20]. Fibrillar $A \beta$ interacts with the cell surface innate immune receptor complex and then stimulates phagocytosis and degradation by microglia [21-26]. The putative role of MARCO has been discussed for internalization and A $31-42$-mediated microglia activation [22, 27]. As some studies have failed to confirm the ability of MARCO to mediate the proinflammatory activity of $A \beta 1$ 42 in mononuclear phagocytes further studies must clarify such interaction [28].
In the present study, we reveal that $\mathrm{N}$-glycan moiety is more critical than SRCR domain for oA $\beta$ internalization mediated by SR-AI. Our results provide insight into the critical role of N-glycosylation of SR-AI, which is a prerequisite for the uptake of $\mathrm{oA} \beta$ by microglia in the initiation stage of $\mathrm{AD}$.

\section{Methods \\ Reagents}

Fluorescein amidite (FAM)-labeled $\mathrm{A} \beta$ 1-42 were purchased from Biopeptide (San Diego, CA). Antibodies against MARCO were purchased from Santa Cruz Biotechnology, Inc. (Santa Cruz, CA). Rabbit antitransferrin receptor (TfR) antibody and Lipofectamine 2000 were purchased from Invitrogen (Carlsbad, CA). Mouse anti- $\beta$-actin antibody was purchased from Sigma-Aldrich (St. Louis, MO). Sulfo-NHS-SS-biotin and NeutrAvidin were purchased from Pierce (Rockford, IL). Peptide N-glycosidase (PNGase F) and endoglycosidase (Endo $\mathrm{H}$ ) were purchased from New England BioLabs (Ipswich, MA).

\section{Modeling}

The crystal structure of mouse MARCO (Protein Data Bank entry 2oy3) [15] was used as a template. A homology modeling method was used to construct the tertiary structure of the SRCR domain of SR-AI [29]. The modeled structure was then optimized, followed by molecular dynamics simulations using the GROMACS (GROningen MAchine for Chemical Simulations) program version 4.5.1 with the AMBER99SB force field [30].

\section{Cell culture}

COS-7 (African green monkey kidney fibroblast-like cell line) cells were maintained in DMEM containing $10 \%$ heat-inactivated fetal bovine serum (FBS), $100 \mathrm{U} /$ $\mathrm{mL}$ penicillin, $100 \mu \mathrm{g} / \mathrm{mL}$ streptomycin, and $2 \mathrm{mM} \mathrm{L}-$ glutamine at $37{ }^{\circ} \mathrm{C}$ in a $5 \% \mathrm{CO}_{2}$ humidified atmosphere. The human embryonic kidney cell line $293 \mathrm{~T}$ (HEK293T) were cultured in DMEM supplemented with $10 \% \mathrm{FBS}, 100 \mathrm{U} / \mathrm{ml}$ penicillin, $100 \mu \mathrm{g} / \mathrm{ml}$ streptomycin, and $2 \mathrm{mM} \mathrm{L}$-glutamine in a humidified $5 \%$ $\mathrm{CO} 2$ atmosphere at $37^{\circ} \mathrm{C}$.

\section{Plasmid construction and transfection}

Human SR-AI cDNA was provided by Dr. Qi Chen (Nanjing Medical University, Nanjing, China). The vector, pcDNA 3.1(+) (Invitrogen, USA) was used to insert full length cDNAs of human SR-AI [4] and MARCO. The sequences of primers and ligation sites used to construct SR-AI variants are shown in Additional file 1: Table S1. Site-directed mutagenesis was performed by using QuickChange II Site-Directed Mutagenesis Kit (Stratagene, La Jolla, CA) according to the manufacturer's instructions. 


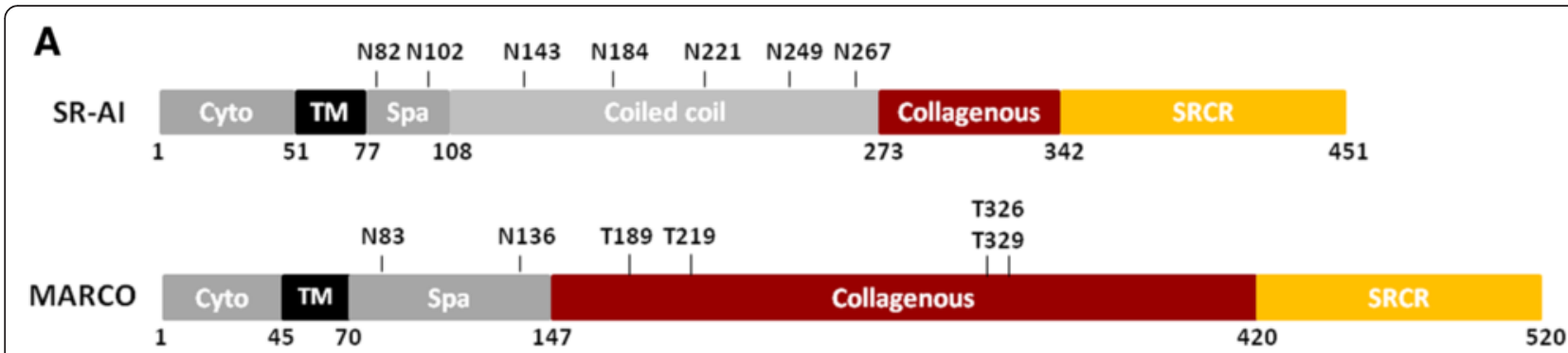

B

SR-AI

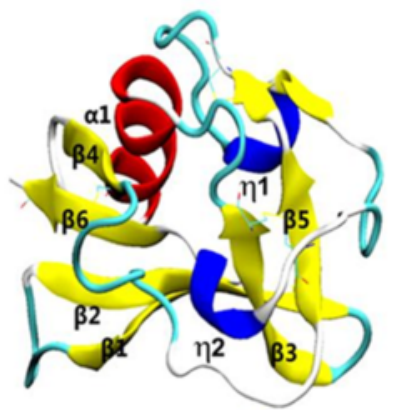

MARCO

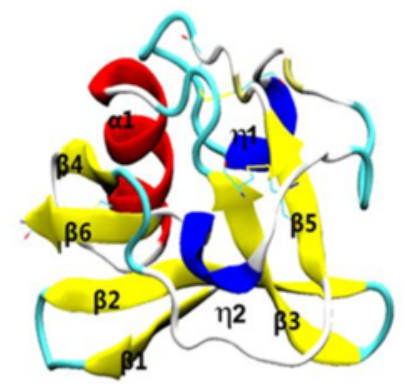

C

SR-AI MARCO

\section{Surface electrostatic potential}
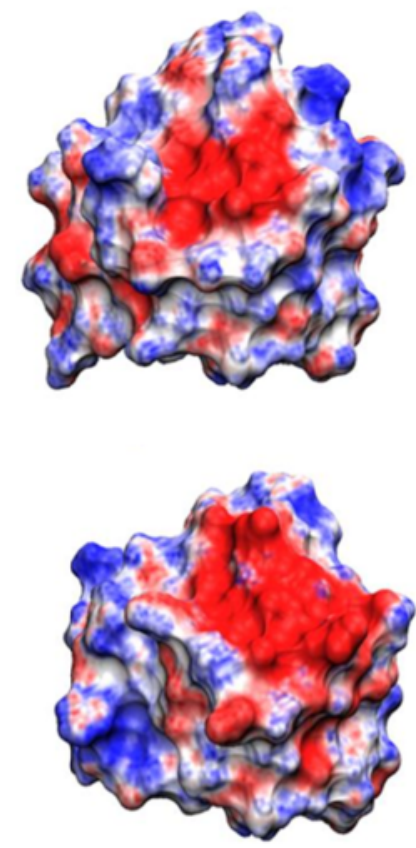

$\stackrel{\beta 1}{\longrightarrow} \stackrel{\beta 2}{\longrightarrow} \mathrm{TT} \stackrel{\beta 3}{\longrightarrow}$ TT m $\stackrel{\alpha 1}{\longrightarrow}$

$\stackrel{\beta 1}{\longrightarrow} \stackrel{\beta 2}{\longrightarrow} \mathrm{TT} \stackrel{\beta 3}{\longrightarrow}$ TT m $\stackrel{\alpha 1}{\longrightarrow}$

336 GEKGSGNTLTPFTKVRLVGGSGPHEGRVE I LHSGQWGT I CDDRWEVRVGQVVCRSLGYPG 412 GEKGERG - ENSVSVRIVGSS - NRGRAEVYYSGTWGT I CDDEWQNSDA I VFCRMLGYSK

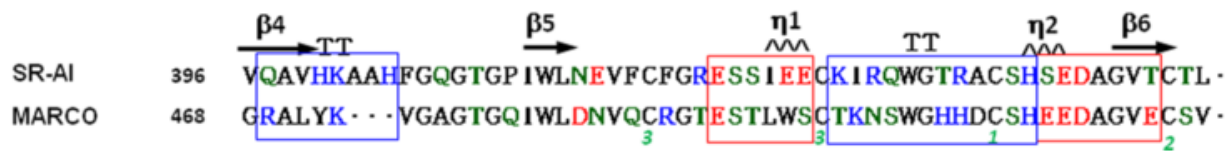

Fig. 1 Modeled structure of the SRCR domain of human SR-Al and MACRO. a Schematic illustration of human MCRCO and SR-Al. The MARCO domains: cytoplamic domain (cyto), transmembrane domain (TM), spacer domain (Spa), coiled coil domain (coiled coil), triple-helical collagenous domain (collagenous), and cysteine-rich C-terminal domain (SRCR). The predicted N-glycosylation sides and amino acid sequence number was marked above and below the schematic illustration, respectively. $\mathbf{b}$ The structure of the SRCR domain of SR-Al and MACRO is composed of six $\beta$-strands ( $\beta 1-6$, yellow), one a-helix ( $a 1$, red), two 310 helices $(\eta 1, \eta 2$, blue), turns (indigo), and loops (gray). Disulfide bonds are shown in orange. The conformation folds with three $\beta$-strands $(\beta 1, \beta 2, \beta 3)$ at the N-terminal region followed by a short turn, $a-h e l i x(a 1)$, and $\beta 4$. Then, there are three long loops, located between $\beta 4$ and $\beta 5$, between $\beta 5$ and $\eta 1$, and between $\eta 1$ and $\eta 2$, ending with $\beta 6$. Surface electrostatic potential representation of the SRCR domain of SR-AI and MACRO with basic (blue) and acidic (red) clusters. c Sequence alignment of human SR-Al and MACRO were displayed using ClustalW2 and ESPrip. The $\beta$-sheets are shown as arrows, and helixes are shown as a saw tooth pattern. Turns are marked as TT. The three pairs of disulfide bonds are labeled as numbers in green 
COS-7 cells $\left(3 \times 10^{5}\right)$ were transfected with $2 \mu$ g SR-AI or variants per well in 6-well plates using Lipofectamine 2000 according to manufacturer instructions. After $24 \mathrm{~h}$, cells were subjected to ligand binding, surface protein biotinylation, and immunocytochemical analyses. The fulllength of human MARCO was provide by Genomic Research Center, National Yang-Ming University (Taipei, Taiwan). The sequences of primers and PCR condition used to construct MARCO variants including deletion and point mutants were listed in Additional file 1: Table S2. Site-directed mutagenesis was performed by using QuickChange II Site-Directed Mutagenesis Kit (Stratagene, La Jolla, CA) according to the manufacturer's instructions. HEK293T cells $\left(3 \times 10^{5}\right)$ were transfected with $2 \mu \mathrm{g}$ MARCO or variants per well in 6-well plates using Lipofectamine 2000 according to manufacturer instructions. After 24 to $48 \mathrm{~h}$, cells were subjected to ligand binding, surface protein biotinylation, and immunocytochemical analyses.

\section{Immunocyochemistry and live immunostaining}

Live cells were incubated with rabbit anti-human SR-A antibody at 1:500 dilution (catalog number sc-20660, Santa Cruz Biotechnology) without permeabilization. Cells were incubated with secondary antibody conjugated to Alexa Fluor 488 to detect surface-targeted SRA. To detect cytosolic SR-A, permeabilized mouse primary microglia were then incubated with rat anti-mouse SR-A (catalog number MCA1322EL, AbD Serotec). Permeabilized human macrophage and transfected COS7 cells were incubated with rabbit anti-human SR-A, followed by incubation with secondary antibody conjugated to Alexa Fluor 594. Coverslips were mounted with Vitashield (catalog number H-1200, Vector Laboratories) and images were taken using a confocal microscope (Olympus, FV-1000 and FV-10i). The experiments were repeated at least three times.

To detect the surface-targeted MARCO, live cells were incubated with anti-MARCO antibody (H190, $1: 100)$ at $4{ }^{\circ} \mathrm{C}$. Cells were then fixed and followed by incubation with secondary antibody conjugated to AlexaFluor 488 or 594 secondary antibodies. The coverslips were mounted in Vitashield (Vector Laboratories, Burlingame, CA) and observed using a Zeiss confocal microscope (LSM780). The experiments were repeated at least three times.

\section{Western blot analysis}

Cells were lysed in lysis buffer $(50 \mathrm{mM}$ Tris, $\mathrm{pH} 7.4$, $150 \mathrm{mM} \mathrm{NaCl}, 1$ \% NP-40, 0.25 \% Sodium deoxycholate and protease inhibitor cocktail. After electrophoresis, proteins were transferred onto PVDF membranes (NEN Life Science Products, Boston, MA). After blocking, the membranes were incubated overnight at $4{ }^{\circ} \mathrm{C}$ with primary antibodies for MARCO at a 1:1,000 dilution and $\beta$-actin at a 1:5,000 dilution. After incubation with secondary antibody (goat anti-mouse antibody or goat anti-rabbit antibody conjugated to horseradish peroxidase), the immune complexes were detected using an enhanced chemiluminescence kit (NEN Life Science Products, Boston, MA). The band intensities were quantified by densitometry. More than three independent experiments were performed.

\section{Surface biotinylation assay}

Surface proteins were labeled with Sulfo-NHS-SS-biotin in PBS-MC according to the manufacturer's instructions (Pierce, Rockford, IL). Briefly, cells were incubated with $0.5 \mathrm{mg} / \mathrm{ml}$ of membrane-impermeable Sulfo-NHS-SSbiotin in PBS-MC on ice for $30 \mathrm{~min}$. Unbound biotin was quenched by Tris buffer $(25 \mathrm{mM}$ Tris- $\mathrm{HCl}$ [pH 8.0], $133 \mathrm{mM} \mathrm{NaCl}$, and $10 \mathrm{mM} \mathrm{KCl}$ ) for $10 \mathrm{~min}$ on ice. Cells were lysed with lysis buffer $(50 \mathrm{mM}$ Tris, $\mathrm{pH} 7.4$, $150 \mathrm{mM} \mathrm{NaCl}, 1$ \% NP-40, 0.25 \% Sodium deoxycholate and protease inhibitor cocktail. Biotinylated proteins (400 mg) were precipitated using $50 \mathrm{ml}$ Neutravidin beads and eluted by boiling in lysis buffer followed by immunoblotting for individual proteins.

\section{Deglycosylation}

Cleavage of the $\mathrm{N}$-glycan was performed using PNGase Fand Endo $\mathrm{H}$ as described [4]. Briefly, total cell lysates and biotinylated surface proteins were denatured in denaturing buffer at $95{ }^{\circ} \mathrm{C}$ for $10 \mathrm{~min}$. The protein mixtures were incubated with PNGase F (500 units) or Endo H (1000 units) for $18 \mathrm{hr}$ at $37{ }^{\circ} \mathrm{C}$. The protein was boiled for $10 \mathrm{~min}$ at $95{ }^{\circ} \mathrm{C}$ subjected to Western blot analysis after adding an equal volume of $2 \times$ laemmli SDS sample buffer (BioRad).

\section{Internalization of oligomeric $A \beta$}

FAM-labeled oligomeric $A \beta(o A \beta)$ was prepared from monomer $A \beta_{1-42}$, synthesized by Biopeptide, as previously described $[3,4]$. The oligomeric $A \beta 42$ preparation preformed in our laboratory has been characterized by atomic force microscope and Sedimentation velocity analysis [3]. The composition of oligomeric A $\beta 42$ in the grown medium remains stable as analyzed by Western blot analysis. SR-A cells were incubated with $1 \mu \mathrm{M}$ FAM-oA $\beta$ in serum-free DMEM at $37^{\circ} \mathrm{C}$ for $1 \mathrm{~h}$. Then, cells were immunostained with the anti-SR-A antibody. Images were taken using a confocal microscope (Olympus, FV-1000 and FV-10i). The experiments were repeated at least three times. The fluorescence intensities of more than 100 SR-A-positive cells in five random fields were analyzed using the MetaMorph software (ver. 7.1; Molecular Devices). 


\section{Statistical analysis}

Data were expressed as mean \pm SEM and the differences between groups were considered significant when the values of $p<0.05$. The comparison between groups was analyzed by one-way analysis of variance (ANOVA) followed by Tukey's Honestly Significant Differences Multiple Comparison Test as post-hoc analysis using GraphPad Prism 4 (GraphPad Software Inc., San Diego, CA, USA).

\section{Results}

Identification of $N$-linked glycosylation sites on SR-Al and MARCO by mutagenesis

Seven potential $N$-linked glycosylation sites were predicted in human SR-AI as those predicted by Asn-X-Ser/ Thr sequence in extracellular domain of SR-BI [17, 19]; these include the asparagines at positions: $82,102,143$, $184,221,249$, and 267 . To determine their roles in structure and function of SR-AI, we mutated these sites individually or in combination by replacing asparagine $(\mathrm{N})$ with glutamine (Q) (Fig. 1a and Additional file 1: Table S1). Their glycosylation and surface targeting of the mutants were then analyzed (Fig. 2). The results showed that the largest molecular weight of the SR-AI mutated at N102Q, N143Q, and N184Q were lower $(\sim 80 \mathrm{kDa})$ than that of wild-type SR-AI ( $95 \mathrm{kDa})$ in both total cell lysates (Fig. 2a) and membrane portion (Fig. 2c), but not in the PNGase F cleaved total cell lysates (Fig. 2b). To go a step further, the effects of double mutations at N102Q, N143Q, and N184Q were examined. Western blot analysis showed that the largest molecular weight of the SR-AI mutated at N102Q-N143Q, N102Q-N184Q and N143Q$\mathrm{N} 184 \mathrm{Q}$ were smaller $(\sim 72 \mathrm{kDa})$ than single mutant $(\sim 80 \mathrm{kDa})$ and wild-type $(\sim 95 \mathrm{kDa})$ in total cell lysates (Fig. 2d). After PNGase F cleavage, the largest molecular weight of N102Q-N143Q, N102Q-N184Q, N143QN184Q and wild type were equally reduced to $55 \mathrm{kDa}$ (Fig. 2e). After Endo $\mathrm{H}$ cleavage, the molecular weight range of wild type SR-AI falls into two parts with 50$60 \mathrm{kDa}$ and 72-95 kDa, respectively. However, SR-A with
A

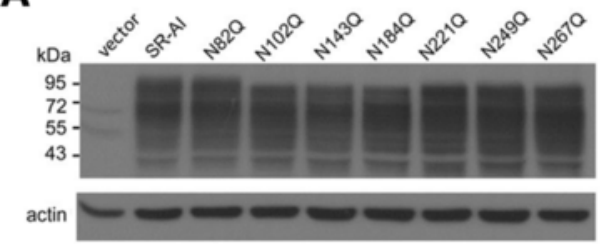

B

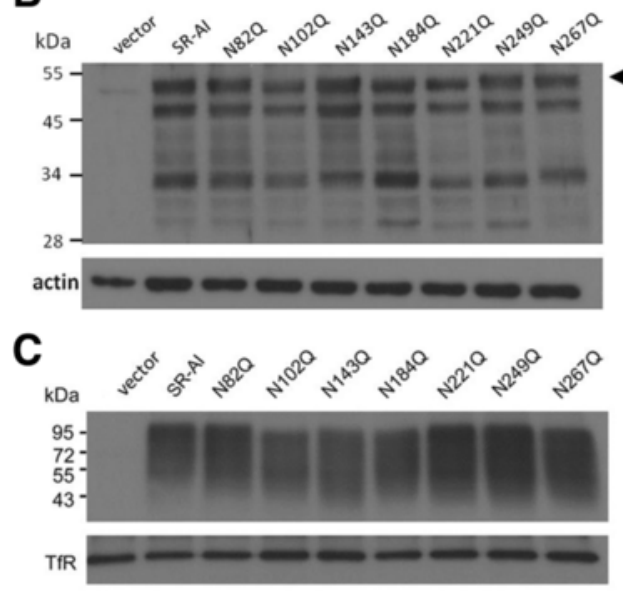

D

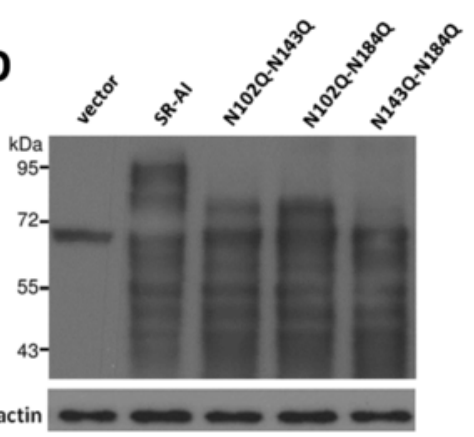

E
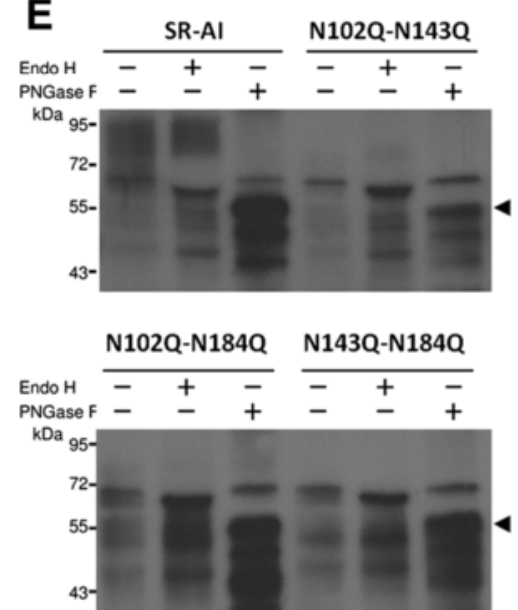

Fig. 2 Identification of the potential N-glycosylation sites of SR-Al. a and $\mathbf{b}$ COS 7 cells were transfected with human SR-Al, the single mutation of asparagine to glutamine at residues $82,102,143,184,221,249$ and 267 . Western blot analysis was performed on the total cell lysates before (a) and after (b) treated by PNGase F, and avidin pull-down of biotinylated cell lysates (c). $\mathbf{d}$ and $\mathbf{e}$ COS-7 cells were transfected with hSR-Al and the double mutation of asparagine $(\mathrm{N})$ to glutamine $(\mathrm{Q})$ residues at 102-143, 102-184 and 143-184. Western blot analysis was performed on the total cell lysates (d) and the PNGase F or Endo $\mathrm{H}$ treated cell lysates $(\mathbf{e})$. The result was repeated for three times $(\mathrm{N}=3)$ and the representative blot was shown 
higher molecular weight was absent in the mutant at N102Q-N143Q, N102Q-N184Q and N143Q-N184Q, suggesting that the $\mathrm{N}$-glycan at 102, 143 and 184 are larger than the other N-glycosylation sites (Fig. 2d).

\section{oA $\beta$ internalization was down-regulated in the cells expressing SR-Al mutated at N102Q-N143Q and N143Q-N184Q}

To determine the surface targeting and oA $\beta$ internalization, live immunostaining of SR-AI and internalization of FAM-labeled oA $\beta$ was performed (Fig. 3). The live immunostaining showed that all mutated SR-AI were surface targeted (Figs. 2b and 3a). We also found that the oA $\beta$ internalization was significantly reduced in the cells expressing SR-AI mutated at N102Q-N143Q and N143Q-N184Q
(Fig. 3b), suggesting that the N-glycosylation at N102N143 and N143-N184 sites are critical for SR-AI to internalized oA $\beta$ (Table 1).

Critical residues in SRCR domain of SR-AI for the surface targeting and $\mathrm{N}$-glycosylation were identified by point mutation

To determine the critical residues of the SR-AI SRCR domain for N-glycosylation and surface targeting of SR-AI, and SR-AI-mediated oA $\beta$ internalization, the positively charged $(R)$, negatively charged $(E)$, polar uncharged $(Q$ and $S$ ) and hydrophobic (G, V, W and F) amino acids in $\beta$ sheet 1 (R351), $\beta$-sheet 2 (E360, R362 and E364), $\beta$-sheet 3 (W371), $\alpha$-helix (Q385), $\beta$-sheet 4 (V399), $\beta$-sheet 5 (W413), disulfide bond (C419), $3_{10}$ helix $\eta 2$ to $\beta$-sheet 6

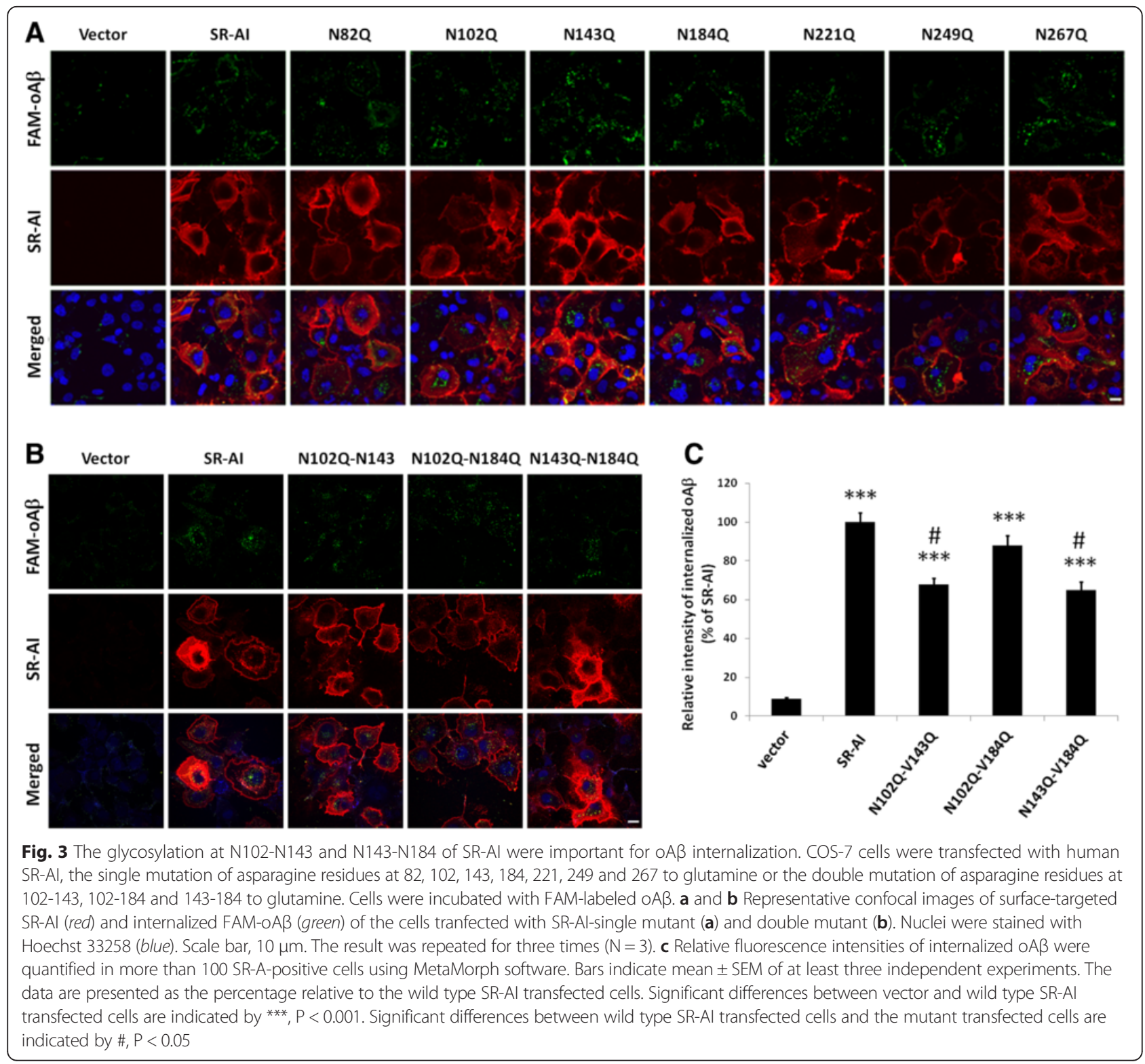


Table 1 Summary of the surface targeting and oA $\beta$ internalization of mutants in N-glycosylation sites of human SR-Al

\begin{tabular}{|c|c|c|c|}
\hline Mutants & $\begin{array}{l}\text { Complex glycan } \\
\text { structure }\end{array}$ & $\begin{array}{l}\text { Surface } \\
\text { targeting }\end{array}$ & $\begin{array}{l}\mathrm{OA} \beta \\
\text { internalization }\end{array}$ \\
\hline $\mathrm{N} 82 \mathrm{Q}$ & + & + & + \\
\hline N102Q & $\downarrow$ & + & + \\
\hline N143Q & $\downarrow$ & + & + \\
\hline N184Q & $\downarrow$ & + & + \\
\hline N221Q & + & + & + \\
\hline N249Q & + & + & + \\
\hline N267Q & + & + & + \\
\hline $\begin{array}{l}\text { N102Q- } \\
\text { N143Q }\end{array}$ & - & + & $\downarrow$ \\
\hline $\begin{array}{l}\text { N102Q- } \\
\text { N184Q }\end{array}$ & - & + & + \\
\hline $\begin{array}{l}\text { N143Q- } \\
\text { N184Q }\end{array}$ & - & + & $\downarrow$ \\
\hline
\end{tabular}

Complex glycan structure is able to be cleavage by PNGase $\mathrm{F}$ but not by Endo $\mathrm{H}$; Hybrid and high mannose type glycans is able to be cleavage by both PNGase $\mathrm{F}$ and Endo $\mathrm{H}$

$\mathbf{+}$, mutants are glycosylated in complex structure, surface-targeted or internalize normal amount of $O A \beta$

-, mutants are not glycosylated in complex structure

$\downarrow$, mutants are less glycosylated in complex structure or internalize less amount $O A \beta$

(D444) and loop (L391, G395-Q397, F418, F420, S424S425, R432 and R437) were site-directed mutated to hydrophobic alanine (A) (Fig. 4 and Additional file 1: Table S2). Moreover, amino acid residuals in $\beta$-sheet 2 (G361), turn (G369) and 310 helix $\eta 2$ (H441) were also site-directed mutated to P, S, and R, respectively (Fig. 4 and Additional file 1: Table S2).

The immunocytochemistry analysis showed that the SRAI mutated at G361P, E364A, H441R, G385A, W413A,
C419A, H441A and D444A were expressed in cytoplasm only (red) and the SR-AI mutated at G369S, L391A, F418A, F420A, R432A, R437A, G395A-Q397A, S424A-S425A and R432A-R437A were expressed in both cytoplasm and cell surface (green and yellow) (Fig. 5a). For detecting the effect of mutation on oA $\beta$ internalization, the cells expressing the SR-AI mutated at G369S, L391A, F418A, F420A, R432A, R437A, G395A-Q397A, S424A-S425A and R432A-R437A were incubated with FAM-oA $\beta$ and internalization were detected. The result showed that the green punta signals were detected in all of detected cells (Fig. 5b).

Two out of 11 surface targeted mutants (i.e. R432A and $\mathrm{R} 437 \mathrm{~A}$ ) and 4 out of 10 intracellular retained mutants (i.e. G361P, E364A, H441R, and D444A) were selected for Western blots analysis. The result showed that the electrophoretic mobility range of the mutant at R432A and R437A were similar to wild type SR-AI (from 45 to $100 \mathrm{kDa}$ ), suggesting that they were glycosylated to a similar extent. Alternatively, the range of electrophoretic mobility of the mutant at G361P, E364A, H441R, and D444A were narrow down (from 55 to $72 \mathrm{kDa}$ ), suggesting that the $\mathrm{N}$-glycosylation of these mutants may be held at a premature stage (Fig. 6a). Furthermore, the surface biotinylation assay showed that only R432A and R437A were surface-targeted (Fig. 6b).

The N-glycosylation status of wild type SR-AI and mutant G361P, E364A, R432A, R437A, H441R, D444A, G395A-Q397A and R432A-R437A were assessed by Western blotting after the cell extracts were incubated with Endo $\mathrm{H}$ and PNGase F (Fig. 6c). The result showed that Wild type SR-AI and mutant R432A, R437A, G395AQ397A and R432A-R437A were sensitive to PNGase F but not to Endo $\mathrm{H}$, indicating the $\mathrm{N}$-linked complex glycans. Alternatively, mutant G361P, E364A, H441R and

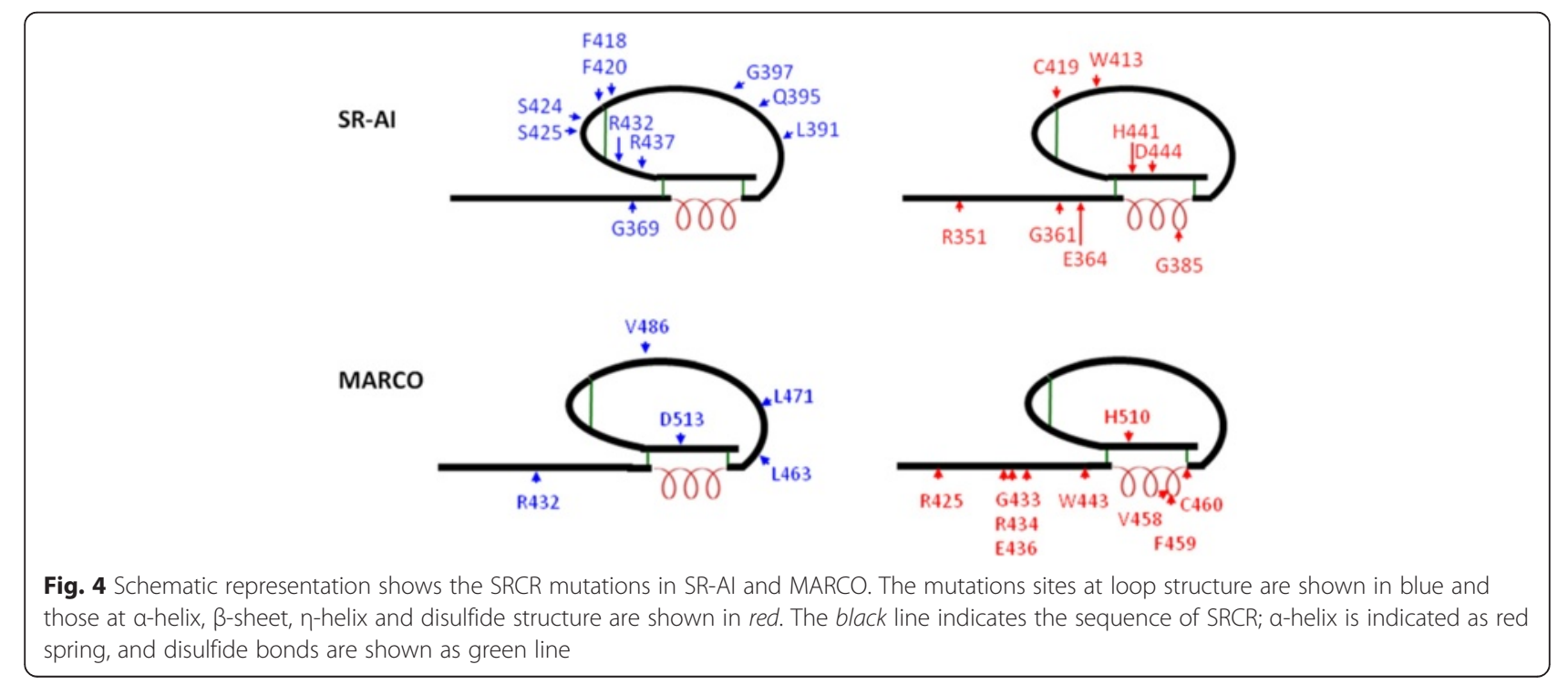



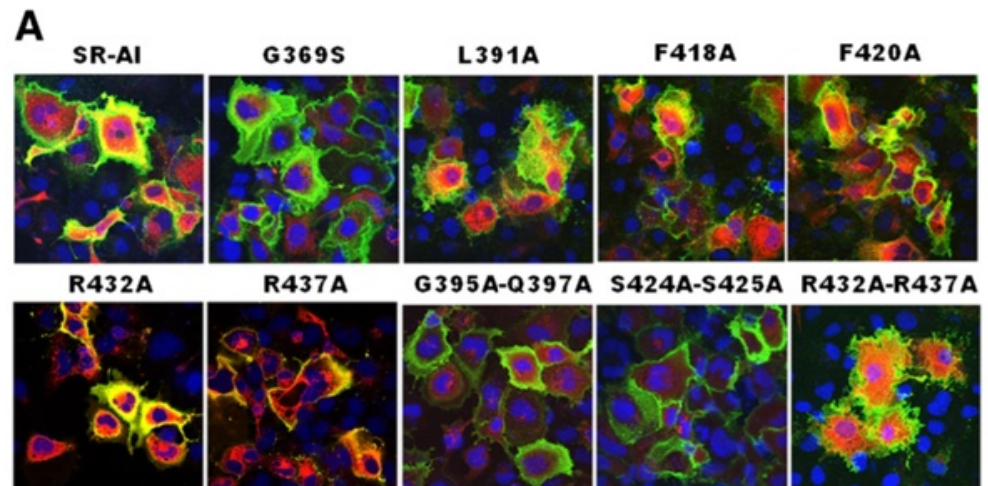

R437A
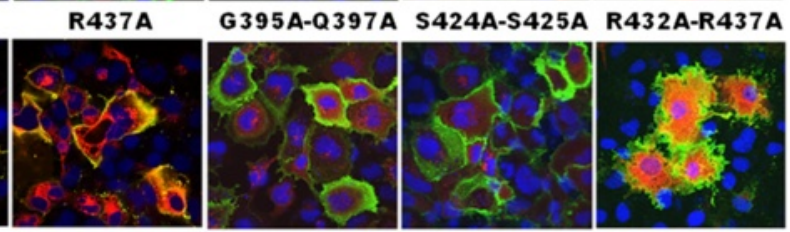

R351A

G361P

F364A
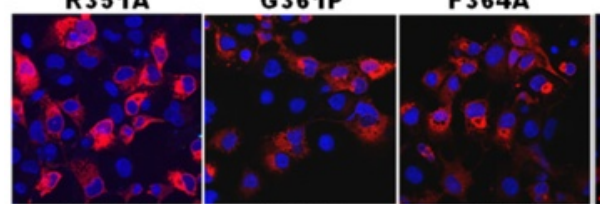

W371A

G385A
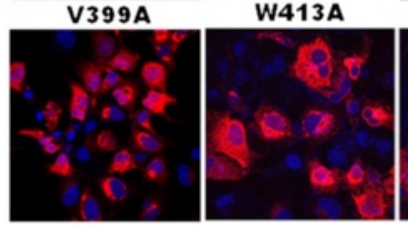

C419
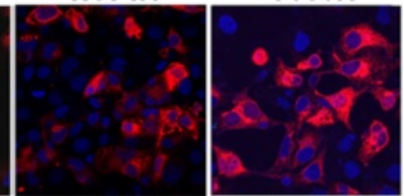

B

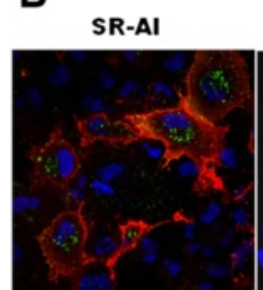

G369S
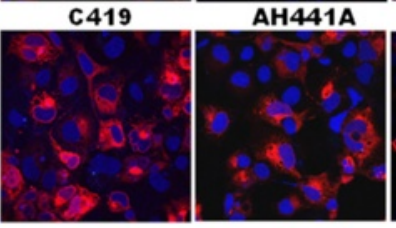

D444A

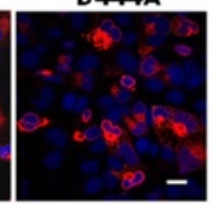

F420A
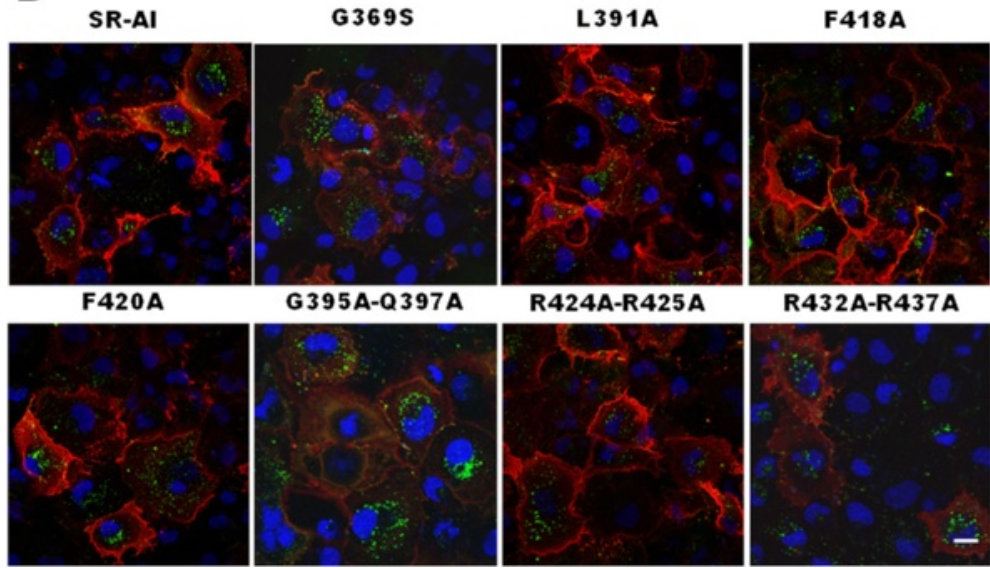

G395A-Q397A

R424A-R425A

R432A-R437A
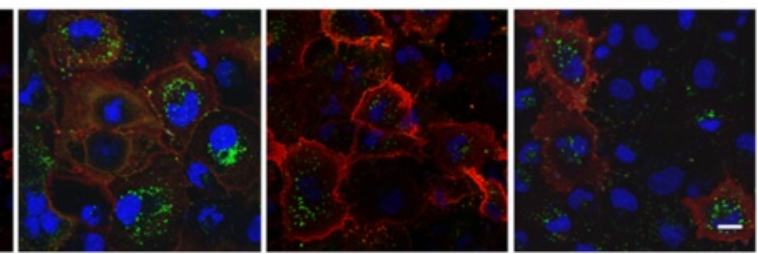

Fig. 5 Critical residues in SRCR domain of human SR-AI for the surface targeting and N-glycosylation were identified by point mutation. COS-7 cells were transfected with wild type SR-AI and SR-AI variants. a Surface-targeted SR-Al and its variants were detected by live immunostaining (green). Cytosolic SR-A and its variants were detected by immunocytochemistry (red). Nuclei were counterstained with Hoechst 33258 (blue). b Cells were incubated with FAM-labeled oA 3 . Representative merged confocal images of surface-targeted SR-AI (red) and internalized FAM-labeled oA $\beta$ (green) were shown. Nuclei were counterstained with Hoechst 33258 (blue). Scale bar, $10 \mu \mathrm{m}$. The result was repeated for four times ( $\mathrm{N}=4$ ) and the representative image was shown

D444A were sensitive to both PNGase F and Endo H, suggesting the high mannose- or hybrid-type glycans (Fig. 6c). These results showed that all mutation in the domains with secondary structure retain receptor intracellularly and abolished N-glycosylation of SR-AI (Table 2).

Next, we assessed the role of SRCR domain in the protein trafficking of MARCO, another member of class I SRCR domain superfamily by expressing deletion variants with serial truncations of the SRCR domain in HEK293T cells. The truncated MARCO mutants 499, 476, 442, 431, and 420 contain 79,56,22,11, and 0 residues of SRCR domain, respectively (Additional file 1: Figure S1A; Additional file 1: Table S4). The comparable enzymatic activities of co-transfected $\beta$-galactosidase across variants suggest that their transfection efficiencies were similar (data not shown). All of the truncated MARCO mutants 

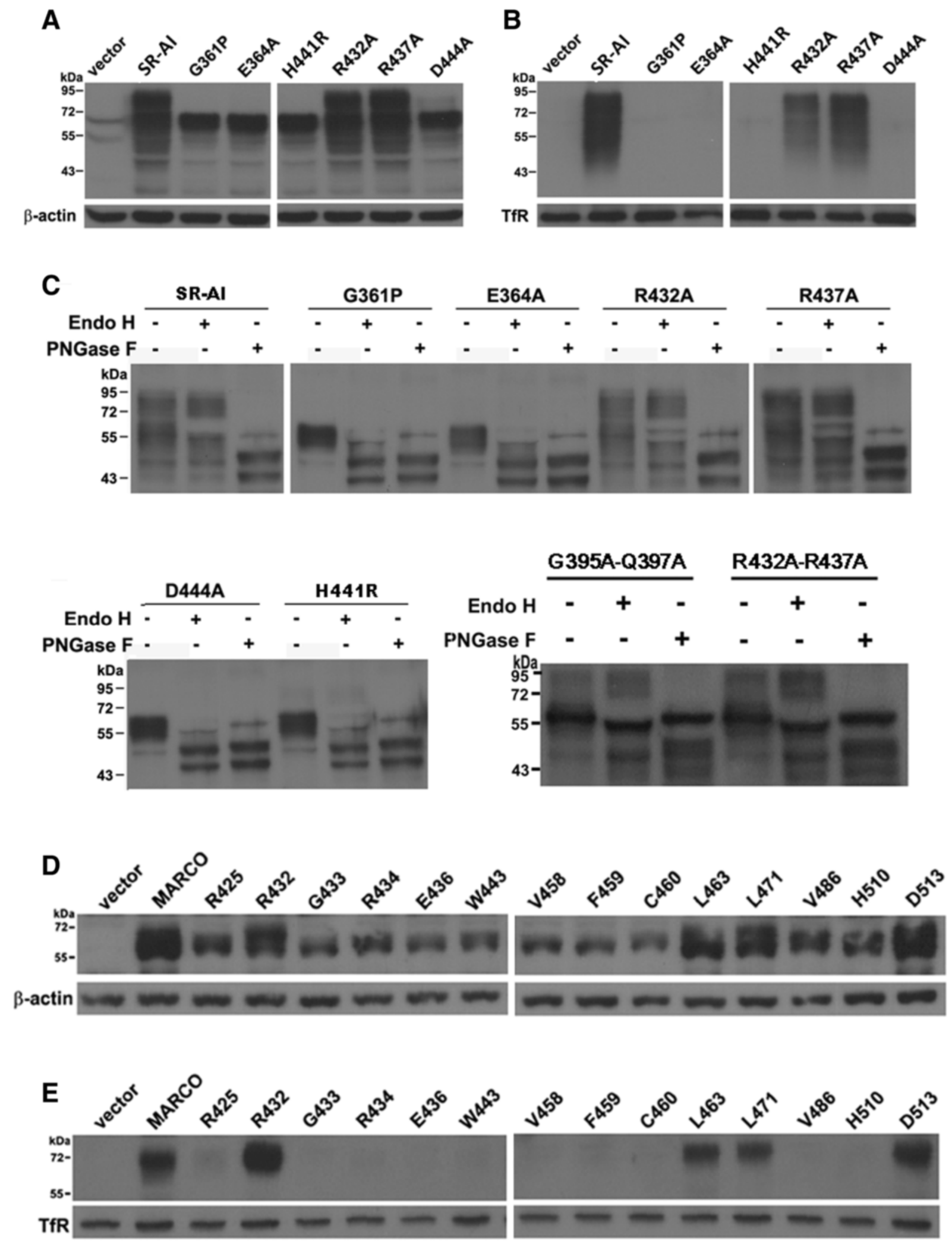

Fig. 6 (See legend on next page.) 
(See figure on previous page.)

Fig. 6 Critical residues in the SRCR domain for the surface targeting and N-glycosylation of SR-Al and MARCO. a-c SR-Al variant G361P, E364A, S369S, L391A, F418A, F420A, G395A-Q397A, S424A-S425A, R432A, R437A, R4321A-R437A, H441R, and D444A were created by site-directed mutagenesis. Total cell lysates (A) and avidin pull-down of biotinylated lysates (B) were subjected to Western blot analysis. Western blot analysis of total cell lysates after PNGase F or Endo H cleavage (C). d-e, HEK293 cells were transfected with MARCO and variant R425A, R432A, G433A, R434A, E436A, W443A, V458A, F459A, C463A, L471A, V486A, H510A and D513A were created by site-directed mutagenesis. Total cell lysates (D) and avidin pull-down of biotinylated lysates (E) were subjected to Western blot analysis. The result was repeated for four times ( $N=4)$ and the representative blot was shown

were able to be expressed in HEK293T cells with the major molecular weight at approximately 60 to $50 \mathrm{kDa}$ (Additional file 1: Figure S1B). However, only the mutant 442, 431 and 420 were surface-targeted (Additional file 1: Figure S1C).

To determine the critical residues of the MARCO SRCR domain for $\mathrm{N}$-glycosylation and surface targeting of MARCO, and MARCO-mediated oA $\beta$ internalization, amino acid side chain in $\beta$-sheet 1 (R425), $\beta$-sheet 2 (R432, G433, G434 and G436), $\beta$-sheet 3 (W443), $\alpha$ helix (I475, V458, F459), disulfide bond (C460), $\beta$-sheet

Table 2 Summary of the surface targeting and $O A \beta$ internalization of mutants in SRCR domain of human SR-AI

\begin{tabular}{|c|c|c|c|}
\hline Mutants & $\begin{array}{l}\text { Mutation } \\
\text { position }\end{array}$ & $\begin{array}{l}\text { Surface } \\
\text { targeting }\end{array}$ & $\begin{array}{l}\mathrm{OA} \beta \\
\text { internalization }\end{array}$ \\
\hline R351A & $\beta 1$ & - & - \\
\hline $\mathrm{E} 360 \mathrm{~A}$ & $\beta 2$ & - & - \\
\hline G361P & $\beta 2$ & - & - \\
\hline R362A & $\beta 2$ & - & - \\
\hline E364D & $\beta 2$ & - & - \\
\hline G369S & Turn & + & + \\
\hline W371A & $\beta 3$ & - & - \\
\hline Q385A & a1 & - & - \\
\hline L391A & Loop & + & + \\
\hline $\begin{array}{l}\text { G395A- } \\
\text { Q397A }\end{array}$ & loop- $\beta 4$ & + & + \\
\hline V399A & $\beta 4$ & - & - \\
\hline W413A & $\beta 5$ & - & - \\
\hline F418A & loop & + & + \\
\hline C419A & disulfide bond & - & - \\
\hline $\mathrm{F} 420 \mathrm{~A}$ & loop & + & + \\
\hline S424A-S425A & loop & + & + \\
\hline R432A & loop & + & + \\
\hline R437A & loop & + & + \\
\hline R432A-R437A & loop & + & + \\
\hline H441R & $\eta 2$ & - & - \\
\hline D444A & $\eta 2-\beta 6$ & - & - \\
\hline
\end{tabular}

Mutation position represents the location of mutated residues in the

simulated-structure of SRCR domain

$\mathbf{+}$, mutants are surface-targeted and do not internalize $o A \beta$

- , mutants are not surface-targeted and do not internalize oA $\beta$
4 (L471), ๆ2 (H510A) and loop (L463, V486, D513) were site-directed mutated to hydrophobic alanine (A) (Fig. 4 and Additional file 1: Table S3). Western blot showed that all of the point mutants were able to be expressed in HEK293T cells with molecular weight at approximately $60 \mathrm{kDa}$ (Fig. 6d). The expression levels of SRCR point mutants G433A, W443A, V458A, and F459A were lower than wild-type MARCO (Fig. 6d) although the transfection efficiency of all point mutants were similar (Data not shown). The surface biotinylation assay and live immunostaining showed that R432A, L463A, L471A and D513A were surface-targeted (Fig. 6e and Table 3 ), and the oA $\beta$ internalization mediate by these mutants were not significantly changed (data not shown).

\section{Discussion}

In the present study, we use live immunostaining, surface biotinylation assay and FAM-labeled oA $\beta$ internalization to assess the function of $\mathrm{N}$-glycosylation and the critical

Table 3 Summary of the surface targeting of mutants in SRCR domain of human MARCO

\begin{tabular}{lll}
\hline Mutants & Mutation position & Surface targeting \\
\hline R425A & $\beta 1$ & $\mathbf{-}$ \\
R432A & Loop- 32 & $\mathbf{+}$ \\
G433A & $\beta 2$ & $\mathbf{-}$ \\
R434A & $\beta 2$ & $\mathbf{-}$ \\
R436A & $\beta 2$ & $\mathbf{-}$ \\
W443A & $\beta 3$ & $\mathbf{-}$ \\
I457A & a1 & $\mathbf{+}$ \\
V458A & a1 & $\mathbf{-}$ \\
F459A & a1 & $\mathbf{-}$ \\
C460A & disulfide bond & $\mathbf{-}$ \\
L463A & loop & $\mathbf{+}$ \\
L471A & $\beta 4-l o o p$ & $\mathbf{+}$ \\
V486A & loop & $\mathbf{-}$ \\
H510A & $\eta 2$ & $\mathbf{-}$ \\
D513A & loop & $\mathbf{+}$ \\
\hline
\end{tabular}

Mutation position represents the location of mutated residues in the simulated-structure of SRCR domain

$\mathbf{+}$ mutants are surface-targeted

- , mutants are not surface-targeted 
residuals of SRCR domain of Human SR-AI and MARCO. Human SR-AI is a transmembrane glycoprotein with seven predicted N-glycosylation sites [4]. However, utilization of the predicted $\mathrm{N}$-glycosylation sites and their roles in surface targeting and functions of SR-AI remained unclear. The previous study has found that preventing Nglycosylation of SR-AI by inhibiting $\alpha$-glucosidases I and II leads to retention of immature N-glycans on SR-AI, but the abilities of SR-AI surface targeting and ligand uptake are abolished [17]. In present study, we identified three N-glycosylation sites critical for the formation of complex-type N-glycans. The mutation of receptor's Nglycosylation sites at N102Q, N143Q, N184Q, N102QN143Q, N102Q-N184Q and N143Q-N184Q significantly reduced receptor's $\mathrm{N}$-glycosylation without affecting its surface targeting. The level of oA $\beta$ internalization was diminished only as the mutation occurred at two successive $\mathrm{N}$-glycosylation sites (i.e. N102Q-N143Q and N143QN184Q). Until now, the role of glycosylation status of scavenger receptor was only reported in two class B receptors. The structure and ligand binding of CD36 and SR-BI are modulated by the status of $\mathrm{N}$-glycan. All 11 potential $\mathrm{N}$-linked glycosylation sites were glycosylated in the murine SR-BI [31]. Mutations at two of these sites at positions 108 and 173 induced fully Endo $\mathrm{H}$-sensitive forms of SR$\mathrm{BI}$ and might have interfered with exit of the receptors from the ER, substantially reducing Golgi-mediated processing. Consequently, these two sites are critical for normal surface expression and efficient lipid uptake. Alternatively, site-directed mutagenesis of human class B scavenger receptor CD36 showed that mature Nlinked glycosylation is not necessary for surface expression and ligand binding [32]. CD36 mutants with fewer glycosylation sites can fold, target to cell surface, and bind ligand. According to our data, double mutants N102Q-N184Q showed low expression level in membrane protein but is able to internalize as much ligand as wild-type SR-AI which was consistent with the study of CD36. Nevertheless, the $\mathrm{N}$-glycosylation in double mutant N102Q-N143Q and N143Q-N184Q abrogated its activity on $\mathrm{oA} \beta$ internalization.

The molecular weight of endogenous and surface protein of MARCO after PNGase F treatment was larger than the predicted molecular weight of MARCO. It is likely that MARCO contain other posttranslational modification. Because MARCO contains four predicted O-link glycosylation sites in collagenous structure (T189, T219, S326, and S329) and average molecular mass of single $O$ link polysaccharide is $1-2 \mathrm{kDa}$, it is possible that the shift of molecular size cause by $O$-glycosylation. The smear band spanning the molecular weight range of 55 to $70 \mathrm{kDa}$ in the cell lysates were PNGase F sensitive,

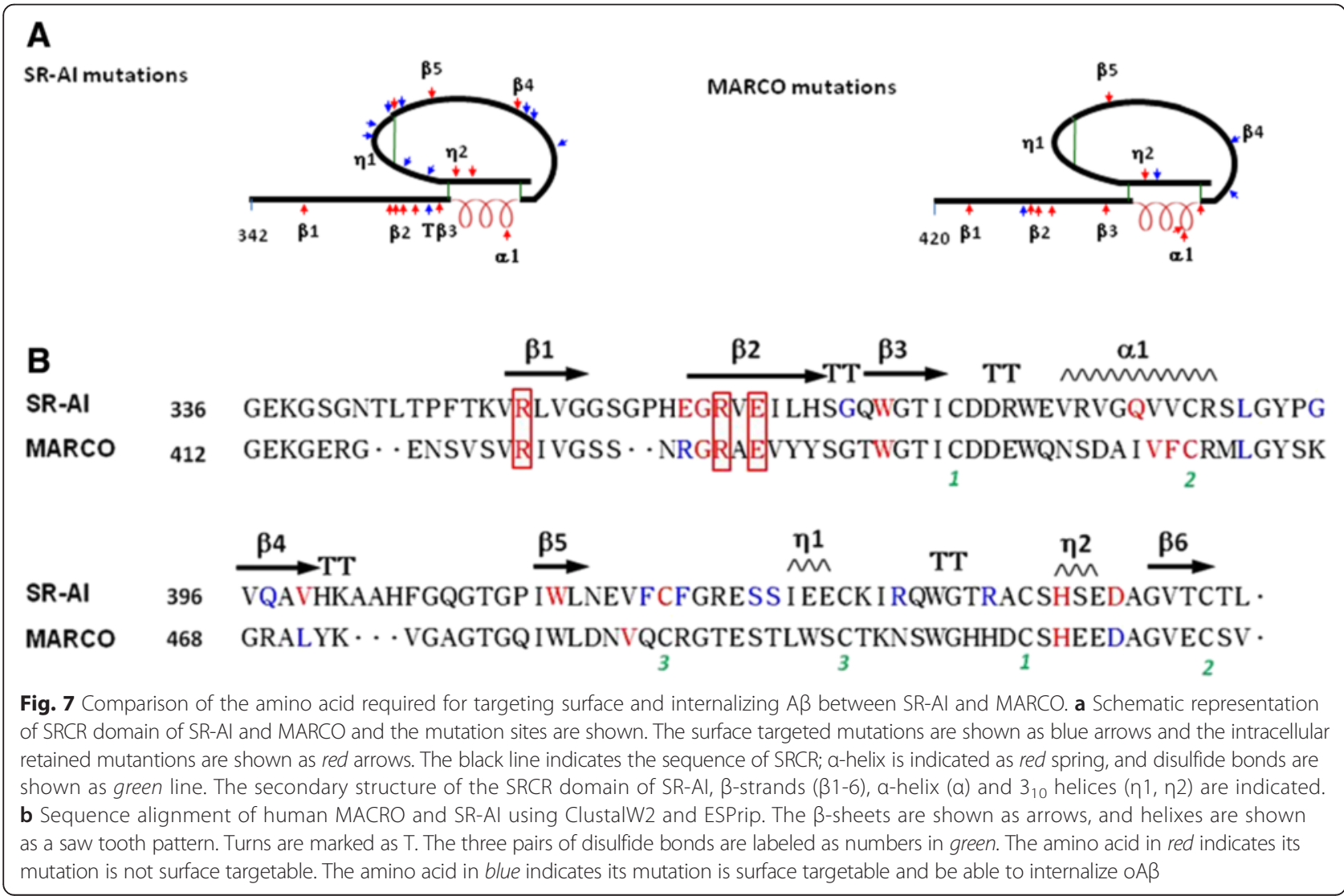


indicating that the MARCO exhibited different extents of $\mathrm{N}$-link glycans. Moreover, $\mathrm{N}$-glycosylation defected MARCO (i.e. N83Q-136Q double mutant) was not expressed on cell surface.

Our previous study has provided evidence that the intact SRCR domain of SR-AI is critical for the protein folding and N-glycosylation. The level of oA $\beta$ internalization was diminished in the cells expressing the surface targeted SRCR truncated variant 371 and 341 [4]. In the present study, the similar result was confirmed on MARCO. Disulfide bonds are important for protein folding and conformational stabilization as well as for protein maturation and trafficking [33]. The globular fold of SRCR domain of monomeric MARCO is stabilized by three disulfide bonds: C447-C508, C459-C517, and C487-C497 [14]. Truncated mutants 499 and 476 reduced the total MARCO expression which may be due to the decrease translation efficiency or increase protein degradation. Compared to truncated mutants 499 and 476, deletion the total cysteine residues mutants $(442,431$, and 420) have higher level of MARCO. The data suggest that disulfide bonds of SRCR domain play a structural role for protein folding. Inhibition of disulfide bond formation of ATP-binding cassette sub-family G member 2 induced protein degradation in proteasomes [34]. In addition, the surface targeted mutant 442 has lower molecular weight than mutants 431 and 420 , suggesting that the glycosylation pattern and polysaccharide length are variant among the three truncated mutants. It is possible that the process of $\mathrm{N}$-glycosylation in MARCO was affected in mutant 442, since glycosylation is important for protein folding and stability, cell adhesion, and receptor targeting [16].

We also provide the first evidence for that mutation of SRCR domain of SR-AI and MARCO at the residual in $\beta$ sheets, $\alpha$-helix and $\eta 2$ and the cysteine residuals for disulfide bond formation abolished receptor's trafficking. The similar clusters of acidic and basic residues in SRCR domain are similar between SR-AI and MARCO (Fig. 1b and c). One RRE motif, located at R351-R362-E364 in $\beta$ sheet 1 and 2 of SR-AI corresponds to R425-R454-E456 of human MARCO (Fig. 7). Three single point mutations at R351A and E364A of human SR-AI and that at R425A of human MARCO impaired receptor surface trafficking and N-glycosylation. This suggests that the SRCR domain of SR-AI may play a predominant role in protein folding. In a dimmer of the recombinant MARCO SRCR domain, $\beta$-sheet 1 , the turn, and $\beta$-sheet 2 form a large $\beta$-sheet via $\beta$-strand swapping of the two monomers [14]. Our results demonstrated that all mutants at the region of $\beta$-sheet, $\alpha$-helix and disulfide bound were retained intracellularly, suggesting that this region is critical for the protein folding and trafficking. Alternatively, all 9 mutations of SR-AI and 3 mutant of MARCO at the residual in turn or loops did not affect receptor's surface trafficking and N-glycosylation. However, the receptor-mediated oA $\beta$ internalization was not significantly affected by those surface targeted mutations of SR-AI.

\section{Conclusions}

In conclusion, our study identifies the critical motifs of SRCR domain regulating the proper folding required for surface trafficking which is prerequisite for exerting diverse functions of human MARCO and human SR-AI. Alternatively, $\mathrm{N}$-glycan moiety is more critical than SRCR domain for SR-A-mediated oA $\beta$ internalization.

\section{Additional file}

Additional file 1: Figure S1. The SRCR domain is critical for the surface targeting and N-glycosylation of MARCO. HEK293 cells were transfected with MARCO and variants with truncated SRCR domain. A. Constructs 499, 478, 442, 491 and 420 MARCO variants with truncated SRCR domains (blue line) and contact collagenous domain (red line). The secondary structure of the SRCR domain of SR-Al, $\beta$-strands ( $\beta 1-6)$, a-helix (a) and 310 helices $(h 1, h 2)$ are indicated in red. Disulfide bonds are shown in green. Total cell lysates (B) and avidin pull-down of biotinylated lysates (C) were subjected to Western blot analysis. The result was repeated for three times and the representative blot was shown. Table S1: Primer sets for expression constructs of SR-A1 mutants at spacer and coiled-coil domain. Table S2: Primer sets for expression constructs of SR-A1 mutants at SRCR domain. Table S3: Primer sets for expression constructs of MARCO point mutants. Table S4: The primer sets for expression construct of MARCO variants. (ZIP $962 \mathrm{~kb}$ )

\section{Abbreviations}

A $\beta$ : Amyloid- $\beta$ peptide; AcLDL: Acetylated low-density lipoprotein; AD: Alzheimer's disease; DMEM: Dulbecco's modified Eagle's medium; FAM: Fluorescein amidite; FBS: Fetal bovine serum; HEK293T: Human embryonic kidney cell line 293 T; SR-A: Scavenger receptor class A; SR-Al: SR-A type I; SR-BI: Scavenger receptor class B type I; SRCR: Scavenger receptor cysteine-rich domain; MARCO: Macrophage receptor with collagenous structure; oA $\beta$ : Oligomeric amyloid- $\beta$ peptide; PNGase F: Peptide N-glycosidase; Endo $\mathrm{H}$ : Endoglycosidase.

\section{Competing interests}

The authors declare that they have no competing interests.

\section{Authors' contributions}

YCH, FSS and FLH performed Western blot and the quantification analysis. CNY, YHL, YJC and SMH constructed expression plasmids with deletion and point mutations. KCT performed molecular structure analysis. HJT and YJS prepared manuscripts. All authors read and approved the final manuscript.

\section{Acknowledgement}

We thank Dr. Qi Chen (Nanjing Medical University, Nanjing, China) and Dr Margaret Dah-Tsyr Chang (National Tsing Hua University, Hsinchu, Taiwan) for providing cDNAs of human SR-Al and MARCO. We thank Drs. Che Ma, Yun-Ru Chen, and Yu-May Lee for critical suggestions on the experimental design. This project was supported by the Ministry of Science and Technology (MOST-1032311-B-010-008; MOST103-2320-B-077-004-MY3), the Ministry of Education Aim for the Top University Plan (010 AC-B5), and the Cheng Hsin General Hospital (104-31; 104-32).

\section{Author details}

${ }^{1}$ Institute of Neuroscience, Brain Research Center, National Yang-Ming University, Taipei 11221, Taiwan, R.O.C. ${ }^{2}$ Department of Physical Medicine and Rehabilitation, Cheng Hsin General Hospital, Taipei 112, Taiwan, R.O.C. ${ }^{3}$ Division of Chinese Materia Medica Development, National Research Institute of Chinese Medicine, Taipei 11221, Taiwan, R.O.C. ${ }^{4}$ Institute of 
Anatomy and Cell Biology, National Yang-Ming University, Taipei 11221, Taiwan, R.O.C. ${ }^{5}$ Center for Neuropsychiatric Research, National Health Research Institutes, No. 35 Keyan Road, Zhunan Town, Miaoli County 350, Taiwan, R.O.C. ${ }^{6}$ Department of Physical Medicine and Rehabilitation, Cheng Hsin General Hospital, Taipei 11220, Taiwan, R.O.C. 'Division of Basic Chinese Medicine, National Research Institute of Chinese Medicine, Taipei 11221, Taiwan, R.O.C. ${ }^{8}$ Institute of Biopharmaceutical Science, National Yang-Ming University, Taipei 11221, Taiwan, R.O.C.

Received: 24 November 2015 Accepted: 3 February 2016 Published online: 18 February 2016

\section{References}

1. Ferreira ST, Lourenco MV, Oliveira MM, De Felice FG. Soluble amyloid- $\beta$ oligomers as synaptotoxins leading to cognitive impairment in Alzheimer's disease. Front Cell Neurosci. 2015;9:191.

2. Zhang H, Su YJ, Zhou WW, Wang SW, Xu PX, Yu XL, et al. Activated scavenger receptor A promotes glial internalization of Aß. PLoS One. 2014;9:e94197.

3. Yang CN, Shiao YJ, Shie FS, Guo BS, Chen PH, Cho CY, et al. Mechanism mediating oligomeric Abeta clearance by naïve primary microglia. Neurobiol Dis. 2011;42:221-30.

4. Huang FL, Shiao YJ, Hou SJ, Yang CN, Chen YJ, Lin CH, et al. Cysteine-rich domain of scavenger receptor Al modulates the efficacy of surface targeting and mediates oligomeric Aß internalization. J Biomed Sci. 2013;20:54.

5. Gough PJ, Greaves DR, Gordon S. A naturally occurring isoform of the human macrophage scavenger receptor (SR-A) gene generated by alternative splicing blocks modified LDL uptake. J Lipid Res. 1998;39:531-43.

6. Post SR, Gass C, Rice S, Nikolic D, Crump H, Post GR. Class A scavenger receptors mediate cell adhesion via activation of $\mathrm{G}(\mathrm{i} / \mathrm{O})$ and formation o focal adhesion complexes. J Lipid Res. 2002;43:1829-36.

7. Cholewa J, Nikolic D, Post SR. Regulation of class A scavenger receptormediated cell adhesion and surface localization by PI3K: identification of a regulatory cytoplasmic motif. J Leukoc Biol. 2010;87:443-9.

8. Chen Y, Wang X, Ben J, Yue S, Bai H, Guan X, et al. The di-leucine motif contributes to class a scavenger receptor-mediated internalization of acetylated lipoproteins. Arterioscler Thromb Vasc Biol. 2006;26:1317-22.

9. Frank S, Lustig A, Schulthess T, Engel J, Kammerer RA. A distinct sevenresidue trigger sequence is indispensable for proper coiled-coil formation of the human macrophage scavenger receptor oligomerization domain. J Biol Chem. 2000;275:11672-7.

10. Santiago-Garcia J, Kodama T, Pitas RE. The class A scavenger receptor binds to proteoglycans and mediates adhesion of macrophages to the extracellular matrix. J Biol Chem. 2003;278:6942-6.

11. Doi T, Higashino K, Kurihara Y, Wada Y, Miyazaki T, Nakamura H, et al. Charged collagen structure mediates the recognition of negatively charged macromolecules by macrophage scavenger receptors. J Biol Chem. 1993; 268:2126-33.

12. Elomaa O, Kangas M, Sahlberg C, Tuukkanen J, Sormunen R, Liakka A, et al. Cloning of a novel bacteria-binding receptor structurally related to scavenger receptors and expressed in a subset of macrophages. Cell. 1995;80:603-9.

13. Martinez VG, Moestrup SK, Holmskov U, Mollenhauer J, Lozano F. The conserved scavenger receptor cysteine-rich superfamily in therapy and diagnosis. Pharmacol Rev. 2011;63:967-1000.

14. Ojala JR, Pikkarainen T, Tuuttila A, Sandalova T, Tryggvason K. Crystal structure of the cysteine-rich domain of scavenger receptor MARCO reveals the presence of a basic and an acidic cluster that both contribute to ligand recognition. J Biol Chem. 2007;282:16654-66.

15. Brannstrom A, Sankala M, Tryggvason K, Pikkarainen T. Arginine residues in domain $V$ have a central role for bacteria-binding activity of macrophage scavenger receptor MARCO. Biochem Biophys Res Commun. 2002;290:1462-9.

16. Marth JD, Grewal PK. Mammalian glycosylation in immunity. Nat Rev Immunol. 2008:8:874-87.

17. Tian G, Wilcockson D, Perry VH, Rudd PM, Dwek RA, Platt FM, et al. Inhibition of alpha-glucosidases I and II increases the cell surface expression of functional class A macrophage scavenger receptor (SR-A) by extending its half-life. J Biol Chem. 2004;279:39303-9.

18. Gu X, Trigatti B, Xu S, Acton S, Babitt J, Krieger M. The efficient cellular uptake of high density lipoprotein lipids via scavenger receptor class B type I requires not only receptor-mediated surface binding but also receptorspecific lipid transfer mediated by its extracellular domain. J Biol Chem. 1998;273:26338-48.
19. Viñals M, Xu S, Vasile E, Krieger M. Identification of the N-linked glycosylation sites on the high density lipoprotein (HDL) receptor SR-BI and assessment of their effects on HDL binding and selective lipid uptake. J Biol Chem. 2003;278:5325-32.

20. Mandrekar S, Jiang Q, Lee CY, Koenigsknecht-Talboo J, Holtzman DM, Landreth GE. Microglia mediate the clearance of soluble Abeta through fluid phase macropinocytosis. J Neurosci. 2009;29:4252-62.

21. D'Andrea MR, Cole GM, Ard MD. The microglial phagocytic role with specific plaque types in the Alzheimer disease brain. Neurobiol Aging. 2004;25:675-83.

22. Mohamed A, Posse de Chaves E. Abeta internalization by neurons and glia. Int J Alzheimers Dis. 2011;2011:127984.

23. Husemann J, Loike JD, Anankov R, Febbraio M, Silverstein SC. Scavenger receptors in neurobiology and neuropathology: their role on microglia and other cells of the nervous system. Glia. 2002;40:195-205.

24. Paresce DM, Ghosh RN, Maxfield FR. Microglial cells internalize aggregates of the Alzheimer's disease amyloid beta protein via a scavenger receptor. Neuron. 1996;17:553-65.

25. Bamberger ME, Harris ME, McDonald DR, Husemann J, Landreth GE. A cell surface receptor complex for fibrillar beta-amyloid mediates microglial activation. J Neurosci. 2003;23:2665-74.

26. Reed-Geaghan EG, Savage JC, Hise AG, Landreth GE. CD14 and toll-like receptors 2 and 4 are required for fibrillar A\{beta\}-stimulated microglial activation. J Neurosci. 2009;29:11982-92.

27. Brandenburg LO, Konrad M, Wruck CJ, Koch T, Lucius R, Pufe T. Functional and physical interactions between formyl-peptide-receptors and scavenger receptor MARCO and their involvement in amyloid beta 1-42-induced signal transduction in glial cells. J Neurochem. 2010;113:749-60.

28. Antic A, Dzenko KA, Pachter JS. Engagement of the scavenger receptor is not responsible for beta-amyloid stimulation of monocytes to a neurocytopathic state. Exp Neurol. 2000;161:96-101.

29. Bordoli L, Kiefer F, Arnold K, Benkert P, Battey J, Schwede T. Protein structure homology modeling using SWISSMODEL workspace. Nat Protoc. 2009;4:1-13.

30. Nguyen TT, Viet MH, Li MS. Effects of water models on binding affinity: evidence from all-atom simulation of binding of tamiflu to $\mathrm{A} / \mathrm{H} 5 \mathrm{~N} 1$ neuraminidase. ScientificWorldJournal. 2014;2014:536084.

31. Vinals $M, X u$ S, Vasile $E$, Krieger M. Identification of the N-linked glycosylation sites on the high density lipoprotein ( $\mathrm{HDL}$ ) receptor SR-BI and assessment of their effects on HDL binding and selective lipid uptake. J Biol Chem. 2003;278:5325-32.

32. Hoosdally SJ, Andress EJ, Wooding C, Martin CA, Linton KJ. The human scavenger receptor CD36: glycosylation status and its role in trafficking and function. J Biol Chem. 2009;284:16277-88.

33. Sevier CS, Kaiser CA. Formation and transfer of disulphide bonds in living cells. Nat Rev Mol Cell Biol. 2002;3:836-47.

34. Wakabayashi K, Nakagawa H, Tamura A, Koshiba S, Hoshijima K, Komada M, et al. Intramolecular disulfide bond is a critical check point determining degradative fates of ATP-binding cassette $(A B C)$ transporter ABCG2 protein. J Biol Chem. 2007;282:27841-6.

\section{Submit your next manuscript to BioMed Central and we will help you at every step:}

- We accept pre-submission inquiries

- Our selector tool helps you to find the most relevant journal

- We provide round the clock customer support

- Convenient online submission

- Thorough peer review

- Inclusion in PubMed and all major indexing services

- Maximum visibility for your research

Submit your manuscript at www.biomedcentral.com/submit
C Biomed Central 